\title{
Erratum to: Cuckoo search algorithm: a metaheuristic approach to solve structural optimization problems
}

\author{
Amir Hossein Gandomi • Xin-She Yang • \\ Amir Hossein Alavi
}

Published online: 12 December 2012

(c) Springer-Verlag London 2012

\section{Erratum to: Engineering with Computers DOI 10.1007/s00366-011-0241-y}

The authors would like to correct errors in the original publication as detailed below:

Since the lower bound of the plate thickness $(t)$ is defined in Sect. 3.2.4, Eq. (33) should be removed.

There were some typos in the cited, earlier articles concerning the problem formulation, which should be corrected as:

$$
\begin{aligned}
g_{1}= & 85.334407+0.0056858 x_{2} x_{5}+0.0006262 x_{1} x_{4} \\
& -0.0022053 x_{3} x_{5} \\
g_{2}= & 80.51249+0.0071317 x_{2} x_{5}+0.0029955 x_{1} x_{2} \\
& +0.0021813 x_{3}^{2}
\end{aligned}
$$

$$
\begin{aligned}
& g_{3}= 9.300961+0.0047026 x_{3} x_{5}+0.0012547 x_{1} x_{3} \\
&+0.0019085 x_{3} x_{4} \\
& f\left(A_{1}, A_{2}\right)=\left(2 \sqrt{2} A_{1}+A_{2}\right) \times l \\
& f\left(A_{s}, b, h\right)=29.4 A_{s}+0.6 b h \\
& f\left(T_{s}, T_{h}, R, L\right)= 0.6224 T_{s} R L+1.7781 T_{h} R^{2}+3.1661 T_{s}^{2} L \\
&+19.84 T_{s}^{2} R
\end{aligned}
$$

In Sect. 3.2.13, the bounds should be $-30 \leq \mathrm{x}_{10}, \mathrm{x}_{11} \leq 30$.

In the last paragraph of Sect. 3, it should read "For solving this problem, CS had a population of 20 cuckoos and 1,000 iterations for each run..."

The online version of the original article can be found under doi:10.1007/s00366-011-0241-y.

A. H. Gandomi $(\bowtie)$

Department of Civil Engineering, Tafresh University,

Tafresh, Iran

e-mail: a.h.gandomi@gmail.com

X.-S. Yang

Mathematics and Scientific Computing, National Physical Lab,

Teddington TW11 0LW, UK

e-mail: xy227@cam.ac.uk

A. H. Alavi

School of Civil Engineering, Iran University of Science

and Technology, Narmak, Tehran, Iran

e-mail: ah_alavi@hotmail.com 